\title{
Del mar español al océano estadounidense, una transición geopolítica
}

\section{From the Spanish Sea to the United States Ocean: A Geopolitical Transition}

DOI: $10.32870 /$ mycp.v9i25.608

\section{Resumen}

El océano Pacífico se integró en la economía global cuando fue posible el tornaviaje desde las islas Filipinas hasta Nueva España. El océano descubierto por Núñez de Balboa en 1513 y surcado por la expedición Magallanes-Elcano, en su viaje de circunvalación de la Tierra, entre 1519-1522, atrajo el interés de otras potencias europeas en los siglos XVII y XVIII, que, hasta entonces, era un mar español. El colonialismo de neerlandeses, británicos, rusos, estadounidenses y, finalmente, franceses transformaron el océano en el centro geopolítico de sus disputas coloniales y sus intereses mercantilistas. Todo ello fue posible por la existencia de un Imperio chino débil, en donde las potencias coloniales establecieron sus áreas de influencia durante décadas, y un Japón aislado en su estado medieval, que utilizó las influencias occidentales para el desarrollo de un gran imperio con fines expansionistas. La presencia del Imperio alemán tuvo escasa influencia y una gran limitación temporal. En este artículo se muestra que, a finales del siglo XIX, la desaparición del Imperio español dio paso al nuevo imperialismo estadounidense y fue el germen de la influencia de Estados Unidos de América en el Pacífico y que transformaría ese océano en el centro de gravedad geopolítico y geoeconómico del nuevo orden mundial.

Palabras clave: Circunnavegación MagallanesElcano, Galeón de Manila, Alfred T. Mahan, Guerra Hispano-estadounidense, Tratado de París de 1898.
Carlos Puente Martín ${ }^{1}$

\begin{abstract}
The Pacific Ocean was integrated into the global economy when it was possible to travel from the Philippines Islands to New Spain, thanks to the navigator and explorer Andrés de Urdaneta. The Ocean discovered by Núñez de Balboa in 1513 and explored by the Magallanes-Elcano expedition, in its circumvallation of the Earth, between 15191522, focused the interest of other European powers in the 17th and 18th centuries that, until then it was just a Spanish sea. Dutch, British, Russians, Americans and finally French colonialism transformed the Ocean into the geopolitical core of their colonial disputes and their mercantilist interests. This situation was possible due to the existence of a weak Chinese Empire, where the colonial powers established their areas of influence for decades, and an isolated Japan with its medieval status, which used Western influences to become a great empire with expansionist purposes. The German Empire had little influence on the Pacific Ocean. This article shows that, at the end of the 19th century, the collapse of the Spanish Empire gave way to the new American imperialism and it was the origin of the influence of United States of America in the Pacific Ocean and transformed it into the geopolitical and geoeconomic center of gravity of the new world order.
\end{abstract}

Key words: Circunnavigation around the Earth Magallanes-Elcano, Manila Galleon, Alfred T. Mahan, Spanish-American War, Treaty of Paris of 1898.

Artículo recibido el 06 de noviembre de 2018 y dictaminado el 07 de septiembre de 2019.

1. Investigador independiente, conferenciante en organismos e instituciones europeas y americanas y Senior Visiting Professor en Universidades y Foros Internacionales. Actualmente reside en Viena, Austria. ORCID: http://orcid.org/0000-0003-1180-4752 Correo electrónico: cpmartin28@gmail.com 


\section{Introducción}

El actual mapa geopolítico de la región del océano Pacífico es el resultado de la geoestrategia que las grandes potencias aplicaron durante los siglos XVIII y xIx. Poco tienen que ver con las primitivas teorías mercantilistas que se desarrollaron desde su descubrimiento para el mundo occidental a partir de 1513 por portugueses y españoles. La llegada de las flotas neerlandesas y británicas no modificó demasiado el perfil de las relaciones de dependencia político-comercial con las metrópolis. La mayor parte de las transformaciones en la región fueron realizadas por compañías mercantiles protegidas por los gobiernos de los Países Bajos y Gran Bretaña. Francia llegó de forma tardía al océano pero su presencia fue importante y pervive aún en las regiones de la Micronesia, al igual que la influencia británica aunque esté enmascarada tras la Commonwealth. Desde un punto de vista geopolítico, la evolución histórica de las naciones se fundamenta en estrategias que se aplican a la protección de intereses, no solamente políticos o económicos sino también aquellos que garantizan la seguridad mediante fronteras firmes y territorios protectores. El sistema político define la forma del Estado, su influencia de poder y su organización, lo que quiere decir que un gran número de naciones pueden adoptar la misma forma de Estado pero no ejercen el mismo poder en una determinada área geográfica. Es indudable que la geopolítica se ha manifestado de forma permanente en las relaciones internacionales de los Estados y se considera el modelo de Haldford J. Mackinder el paradigma de la Geopolítica realista que tuvo lugar en el océano Pacífico. ${ }^{2}$

Mackinder ${ }^{3}$ fue el defensor más firme del Reino Unido y la existencia del Imperio británico como el paradigma del modelo de relaciones entre el centro y la periferia. En su obra Britain and the British Seas (Gran Bretaña y los mares británicos) defendía que la hegemonía que Inglaterra ejercía en

2. El profesor Peter J. Taylor subraya que "the starting point for almost all discussions of geopolitics is Sir Haldford Mackinder's Heartland Theory. Despite it is neglect in geography it remains probably the most well-known geographical model throughout the world" (Taylor, 1985, p. 37 y ss). Traducción del autor al español: el punto de partida para la mayoría de los debates geopolíticos es la Teoría del corazón continental. A pesar de que ha sido abandonada es probablemente el modelo geográfico más conocido.

3. Halford John Mackinder (1861-1947) fue un geógrafo y geopolítico británico. Perteneció a la Royal Geography Society. Algunas de sus obras son: On the Scope and Methods of Geography, publicada en 1887; Britain and the British Seas, aparecida en 1902; The Geographical Pivot of History, publicada en 1904 y Democratic Ideals and Reality, editada en 1919. 
el mundo dependía del dominio de los mares por la Royal Navy (Mackinder, 1902). Contraponía la necesidad de un control continuo marítimo frente a los grandes imperios terrestres, que no tenían necesidad de ello, pero esta teoría ignoraba la existencia del primer Imperio discontinuo de la Edad Moderna, que fue el Imperio español. El océano Pacífico fue conocido durante mucho tiempo como el "mar español", cuando solo los navegantes y exploradores españoles surcaban las aguas del "mar del Sur", y la actual presencia de los Estados Unidos de América ${ }^{4}$ en todos los océanos confirmaría la teoría de Mackinder.

El modelo de Mackinder describía el sistema mundial como una "isla mundo" con seis áreas donde se ejerce un dominio diferente: Europa central y occidental, Extremo Oriente y sudeste Asiático, Oriente Medio, norte de África, África del Sur y Eurasia. Para Mackinder Eurasia era el centro del mundo y lo denominaba Pivot area (región pivote) pues pensaba que quien controlara esta región dominaría el mundo. El profesor Peter J. Taylor (1985, pp. 37-40) subraya que el modelo de Mackinder se fundamenta en una interpretación muy restrictiva y manifiesta que

con las exploraciones marítimas desde 1492 se inicia la era colombina, en la que el equilibrio de poder se inclina decisivamente hacia las potencias costeras, especialmente Gran Bretaña...La región pivote era definida en términos de una zona inaccesible para las potencias marítimas y estaba rodeada por una protección interior (inner crescent) en la Europa continental y por una protección exterior (outer crescent) en las islas y continentes alrededor de Eurasia. ${ }^{5}$

Mackinder, en The Rivalry of Empires (La rivalidad de los imperios) establecía un paralelismo entre la expansión de los navegantes de la península Ibérica y los rusos a través de las estepas asiáticas. Estaba convencido de la superioridad de las naciones que dominaban los océanos, insistiendo constantemente en

4. El nombre oficial del país norteamericano es United States of America por lo que en idioma español se utilizará Estados Unidos de América, excepto cuando en un documento se utilice Estados Unidos.

5. El profesor Peter J. Taylor realizó algunos comentarios explicativos a la "Teoría del corazón continental" (Heartland Theory) de Mackinder, cuya versión original es: "The land power versus sea power"... With the age of maritime exploration from 1492, however, we enter the Columbus era when the balance of power swung decisively to the coastal powers notably Britain.... The pivot-area was defined in terms of a zone not accessible to sea-power and was surrounded by an inner crescent in mainland Europe and Asia and an outer crescent in the islands and continents beyond Eurasia" (Taylor, 1985, pp. 37-40). 
este hecho con base en la posición de Inglaterra y de su poder naval. Decía Mackinder:

Podría trazarse un interesante paralelismo entre el avance de los marinos occidentales por el océano y el avance de los cosacos rusos a través de las estepas del 'corazón continental'. El cosaco Yermak atravesó los Urales y cabalgó por Siberia en 1533, es decir una docena de años después del viaje de Magallanes alrededor del mundo. (Mackinder, 1919, p. 148). ${ }^{6}$

Mackinder se refiere a acciones geopolíticas concretas que cambiaron el destino de Europa, con una argumentación que no justifica completamente la política exterior de las grandes potencias. Inglaterra desarrolló una marina conforme a su situación geopolítica desde el reinado de Enrique VII y, especialmente, Enrique VIII, a quien se considera el "padre de la Royal Navy". Desde esta perspectiva, la geoestrategia militar de Napoleón Bonaparte podría estar condicionada por el origen insular del Emperador aunque fue ineficaz frente a los británicos. Mackinder decía sobre este tema que

Napoleón fue derrotado parcialmente por el agotamiento de los franceses pero fundamentalmente porque su imperio estaba rodeado por el poder marítimo de Gran Bretaña, ya que ésta podía recibir suministros del exterior de Europa y bloquear a Europa occidental de tales suministros. (Mackinder, 1919, p. 156).?

Sin embargo no todas las naciones que construyeron grandes imperios tuvieron grandes flotas, esto es evidente cuando se comparan los ejemplos de los imperios terrestres de Europa y Asia. En el otro extremo Japón y Estados Unidos de América, que son "islas geopolíticas", solamente contaron con importantes flotas en épocas tardías. En el caso de España es paradigmático el nexo entre el poder marítimo y la construcción de un imperio, pues cuando España perdió su Armada también perdió su imperio.

6. La version original de Halford John Mackinder (1919, p. 148) es "A most interesting parallel might be drawn between the advance of the sailors over the ocean from Western Europe and the contemporary advance of the Russian Cossacks across the steppes of the Heartland. Yermak, the Cossack, rode over the Ural Mountains into Siberia in 1533, within a dozen years, that is to say, after Magellan's voyage round the world..."

7. La cita de Mackinder (1919, p. 156) sobre la importancia de Gran Bretaña como potencia maritima es: "Napoleon was brought down partly by the exhaustion of his French man-power, but mainly because his realm of West Europe was enveloped by British sea-power, for Britain was able to bring to herself supplies from outside Europe and to cut West Europe from similar supplies..." 
En Estados Unidos de América fue Alfred.T. Mahan ${ }^{8}$ quien alentó la política imperialista del presidente Theodore Roosevelt y, posteriormente, en Alemania triunfaron las ideas del general K. Haushofer con la descripción de unos principios que más tarde fueron el fundamento de la geopolítica nazi, basada en el concepto de la necesidad de un espacio vital para el asentamiento de una población considerada racialmente superior. La influencia de las teorías de Alfred T. Mahan es significativa, no solo en el gobierno estadounidense sino también en el desarrollo de la marina de países como Japón y Alemania, defendiendo la supremacía naval como base de la hegemonía de un país. Realizó profundos estudios para demostrar que en la estrategia expansionista de Estados Unidos de América fue decisivo el poder naval de su país, lo que era una geopolítica continuista del imperialismo británico.

La concepción geográfica de estos autores inspiró a Karl Haushofer, ${ }^{9}$ que fue difusor y creador de la teoría del espacio vital o "lebensraum" en la que se basaron los nazis en Alemania para justificar su ambición expansionista que provocó el estallido de la II Guerra Mundial. Haushofer tenía una formación militar y geográfica muy sólida, y en 1908 viajó a Japón como observador, participando en la modernización de su organización militar, lo que le permitió adquirir amplios conocimientos de aquél país. Había tenido estrechos contactos con la más alta jerarquía del Partido nacionalsindicalista alemán, especialmente con Rudolf Hess, en cuya ideología influyó, pero intelectualmente hay que buscar sus raíces en Ratzel y Mackinder de quienes recogió las teorías del "lebensraum" (espacio vital) y del "heartland" (corazón continental). El profesor Peter J. Taylor dice que del primero (Ratzel) adoptó la idea del 'lebensraun' (espacio vital) y la necesidad de grandes regiones políticamente

8. Alfred Thayer Mahan (1840-1914) fue un almirante e historiador estadounidense que participó en la Guerra de Secesión de Estados Unidos y en la Guerra Hipano-estadounidense. Fue el director de la Escuela Naval de Guerra de Newport. Sus obras más importantes son The influence of Sea Power upon History (La influencia del poder naval en la Historia) publicada en 1890 y The Influence of Sea Power upon the French Revolution and Empire (Influencia del poder naval en la Revolución francesa y en el Imperio) aparecida en 1897.

9. Karl Ernst Haushofer (1869-1946). Fue un militar y geógrafo alemán y uno de los principales ideólogos del "Lebensraum" (espacio vital). Participó como general en la I Guerra Mundial y, en 1919. Sus principales obras son "Dai Nihon" (El gran Japón) publicada en 1913, "Macht und Erde” (El poder y la tierra), aparecida en 1932, y "Weltpolitik von Heute" (La política mundial hoy), publicada en 1935. 
unidas, y del último (Mackinder) tomó la teoría del 'heartland' (Taylor, 1985, pp. $40-41) .^{10}$

La estructura de este trabajo sigue una lógica espacial y una metodología histórica, sin perjuicio de que por necesidades de ubicación de hechos ya mencionados se requiera una retroalimentación de datos con expresa cita de su relación temporal. No es que no se respete el desarrollo de algunos acontecimientos, sino que al abordar nuevos hechos es necesario repetir el origen de la información o retrotraerse en el tiempo para explicar una realidad geopolítica más actual. Por lo tanto, en primer lugar es necesario delimitar el espacio, referencias geográficas, y los actores, en este caso los estados que contribuyeron a delimitar el océano Pacífico como un escenario geopolítico. Ningún experto puede pensar que se trata de explicar la actividad geopolítica de varios siglos en unas cuantas páginas. Además no puede esperarse una proporcionalidad entre los distintos actores geopolíticos ya que este trabajo se circunscribe a la sucesión temporal del Imperio español por un emergente Imperio estadounidense. En la última parte del trabajo se enfoca al fin del ciclo geopolítico del Imperio español, que ya estaba en decadencia desde el primer tercio del siglo xix y se describe la transición al nuevo ciclo de hegemonía estadounidense.

\section{El descubrimiento del mar del Sur y la exploración del océano Pacífico}

La llegada de los españoles a América con Cristóbal Colón, en 1492, puso fin a la "ilusión espacial geopolítica", pues el navegante genovés desconocía la existencia del continente recién descubierto y siguió pensando durante mucho tiempo que las tierras recién descubiertas para los europeos eran en realidad parte de Asia, las Indias. Existía un error en la apreciación de la distancia entre Europa y Asia. Colón pretendía llegar a las Indias de donde procedían las especias tan apreciadas en Europa, que debían estar situadas próximas a China (Catay) y Japón (Cipango). Marco Polo ${ }^{11}$ había llegado hasta China

10. Peter J. Taylor señala sobre Haushofer: "from the former (Ratzel) he adopted the ideas of 'lebensraum' (living place) and the resulting need for large regions of political unity. From the latter (Mackinder) he borrowed the heartland theory as a key to understanding Germany's position in the world" (Taylor, 1985, pp. 40-41).

11. El comerciante veneciano Marco Polo viajó hasta China recorriendo la "Ruta de la Seda" y relató en su libro Il Millione las experiencias del grandioso viaje que realizó en el siglo XIII, que sirvió de guía para muchos estadistas y aventureros. 
pero, en El libro de las Maravillas hace referencias a la existencia de una gran isla a la que los chinos llamaban en su idioma "Cipango", y que "es una isla a Levante que está a 1.500 millas apartada de la tierra en alta mar. Es una isla muy grande" (Polo, s.f. p. 133), también menciona "que cuando se parte de Ciamba, entre Mediodía y Sudoeste, a 1500 millas se llega a una isla llamada Java. Según los navegantes, es la isla mayor que hay en el mundo, y tiene más de tres millas de costa" (Polo, s.f. p. 138) y al reino de Sumatra que dice encontrarse en las "proximidades de Basmán" (Polo, s.f. p. 141); también refiere que "esta región está muy alejada del camino de la India, y os dije que se llamaba mar de la China, y quiero que sepáis lo que llamo mar Océano. Pues se dice mar de Inglaterra o mar de la Rochela; así, aquí mar de China y mar de Indias, pero todos éstos son un común denominador, que es el mar Océano" (Polo, s.f. p. 137). Cuando Marco Polo avistó el mar Océano también creyó estar ante el océano Atlántico desde el Oeste.

Hace más de 500 años Europa tuvo conocimiento de un nuevo "mar", con motivo del avistamiento de sus aguas por el explorador español Vasco Núñez de Balboa, ${ }^{12}$ tras atravesar el istmo de Panamá desde el mar Caribe. Tomó posesión del nuevo mar el 25 de septiembre de 1513 y le bautizó con el nombre de "Mar del Sur". Fernando de Magallanes durante su viaje de circunnavegación, en 1520, lo denominó océano Pacífico porque disfrutó de una travesía tranquila y pacífica. El 7 de junio de 1494 los Reyes Católicos, reyes de Castilla y Aragón, Isabel y Fernando, y el rey de Portugal, Juan II, habían firmado, en Tordesillas (Valladolid), el acuerdo que se conoce como Tratado de Tordesillas, para delimitar las zonas de conquista y dominio después del descubrimiento por Cristóbal Colón de las nuevas tierras y mares. Se estableció una línea divisoria norte-sur a lo largo del océano Atlántico. Este acuerdo se considera el primer tratado geopolítico del mundo occidental. El tratado fue refrendado en Arévalo por los Reyes Católicos el 2 de julio de 1494 y Juan II hizo lo propio el 5 de septiembre en Setúbal. Aunque se estipulaba que el tratado sería confirmado por el Papa, Alejandro VI nunca lo hizo y solo su sucesor, Julio II, lo confirmó en 1506.

El Tratado de Tordesillas establecía una nueva línea de demarcación de la influencia entre portugueses y españoles por el meridiano que pasa a 370

12. Vasco Núñez de Balboa (1475-1519) explorador y conquistador español nacido en Jerez de los Caballeros (Badajoz) y el primer europeo que avistó el nuevo océano. Fue gobernador de Veragua, gobernador del Darién y gobernador de la provincia de Panamá y Coiba y Adelantado de la Costa del mar del Sur. Murió decapitado en Acta (Panamá), acusado de traición por su suegro, el gobernador Pedro Arias de Ávila. 
leguas al oeste de las islas de Cabo Verde, es decir el meridiano a $46^{\circ} 37^{\prime}$ longitud oeste, que corresponde al que pasa por la actual ciudad de Sao Paulo. Esta decisión supuso para Portugal el acceso a las tierras americanas y la posterior conquista, en 1500, del actual Brasil por Pedro Álvarez Cabral. Por este acuerdo Castilla también renunciaba a los derechos adquiridos en el norte y noroeste de África. ${ }^{13}$ El Tratado de Tordesillas tuvo una vigencia formal, con numerosas violaciones, hasta que el Tratado de Madrid ${ }^{14}$ de 1750 anuló la línea divisoria establecida en el Tratado de Tordesillas. Posteriormente, el Tratado de 1750 fue anulado por el Tratado de El Pardo de 1761, restableciendo el contenido del original Tratado de Tordesillas y su línea de demarcación, hasta que definitivamente fue abolido por el Tratado de San Ildefonso firmado el 1 de octubre de 1777. Si bien por el océano Atlántico los límites territorialesmarítimos estaban más o menos delimitados, esto no ocurría en el océano Pacífico, en las antípodas de las dos potencias marítimas de la época, lo que provocó no pocas controversias e, incluso, una ignorada guerra entre ambas naciones a miles de kilómetros de las metrópolis.

Desde época remota, los europeos siempre conocieron el océano que existía por el Oeste y los asiáticos siempre fueron conscientes del océano que bañaba sus costas por el Este. Lo sorprendente era que tanto los habitantes de "Cipango" como los mongoles, que desde el norte de Asia habían construido el mayor imperio jamás conocido, no hubieran llegado a las costas del continente que luego se llamaría América, aunque intentaron desembarcar en "Cipango". Es uno de los grandes enigmas de la historia y no hay suficientes vestigios para demostrar que algunos conocimientos geográficos pudieron

13. En el Tratado de Tordesillas se subraya: "Que se haga y asigne por el dicho mar océano una raya o línea derecha de polo a polo, del polo Ártico al polo Antártico, que es de norte a sur, la cual raya o línea e señal se haya de dar e dé derecha, como dicho es, a trescientas setenta leguas de las islas de Cabo Verde para la parte de poniente,... Y que todo lo que hasta aquí tenga hallado y descubierto y de aquí adelante se hallase y descubriere por el dicho señor rey de Portugal y por sus navíos, así islas como tierra firme, desde la dicha raya arriba, ..., que esto sea y quede y pertenezca al dicho señor rey de Portugal y a sus subcesores para siempre jamás. Y que todo lo otro, así islas como tierra firme, halladas y por hallar, descubiertas y por descubrir, que son o fueren halladas por los dichos señores rey y reina de Castilla y de Aragón, etc., y por sus navíos, desde la dicha raya" (Tratado de Tordesillas, 1494).

14. El texto del Tratado de Madrid dice: "Artículo I: El presente tratado será el único fundamento y regla que en adelante se deberá seguir para la división y límites de los dominios en toda la América y en Asia; y en su virtud quedará abolido cualquier derecho y acción que puedan alegar las dos Coronas, con motivo de la bula del Papa Alejandro VI, de feliz memoria, y de los tratados de Tordesillas, de Lisboa y Utrecht, de la escritura de venta otorgada en Zaragoza, y de otros cualesquiera tratados, convenciones y promesas..." (1750). 
llegar a Europa y constituir la guía para emprender una aventura que no era ni mucho menos "rumbo a lo desconocido".

Cuando los españoles llegaron a Filipinas atravesando el océano Pacífico de Este a Oeste se planteó el problema del regreso al continente americano desde el archipiélago filipino. Tras algunos intentos, como explica el profesor Carlos Martínez Shaw, el éxito de encontrar la ruta de regreso desde Extremo Oriente hacia América, es decir el tornaviaje, corresponde a dos personajes: primero, el noble Alonso de Arellano, al frente del patache 'San Lucas', tuvo éxito en su regreso por libre a la costa occidental de América el 17 de julio de 1565. Al no ser un viaje oficial, todo el mérito se ha atribuido al viaje ordenado por Miguel López de Legazpi al mexicano Felipe de Salcedo al frente de la nave 'San Pedro' con Andrés de Urdaneta como piloto, que culminó con éxito el tornaviaje (que sería el segundo) el 8 de octubre de $1565 .{ }^{15}$ Desde entonces el océano Pacífico se integró en el primer proceso de globalización, convirtiendo la ruta del "Galeón de Manila" en la primera ruta comercial de la economía global, que duró con las mismas características hasta 1815, cuando las colonias españolas en América lograron la independencia y la ruta a Filipinas tuvo que bordear África por el Cabo de Buena Esperanza. George Modelski subraya que la aparición del moderno sistema-mundo se remonta a la firma del Tratado de Tordesillas y el establecimiento del "Galeón de Manila". ${ }^{16}$

La presencia de los españoles en las costas americanas del Pacífico se extendió desde la Baja California, en Nueva España, hacia el sur en los territorios que formarían el Virreinato del Perú. En 1533, Fortún Ximénez ${ }^{17}$ alcanzó la Baja California donde fundó la primera colonia europea, que Francisco de Ulloa ${ }^{18}$ certificó que era una península alargada y no una isla como se creía.

15. Agradezco al profesor Carlos Martínez Shaw la cortesía de atender mi consulta sobre este controvertido tema que, sin duda, queda completamente aclarado.

16. Afirma Modelski que “...in 1494 Treaty of Tordesillas that created a new global political regime for the oceanic system without touching upon, or interfering with, national territorial arrangements" y añade que "...the opening of a direct sea route between Europe, India and China, as well as the discovery of America, both circa 1500, transformed this system and drastically raised the intensity of interactions within it"..."Navigators sailed around the globe, and Europe an China were linked not only by the Indian Ocean route but soon also by traffic across the Pacific, via Manila galleon for Acapulco". (Modelski, 1987, pp. 22, 25 y 69).

17. Fortún Ximénez fue un marino español que envió Hernán Cortés para explorar la costa norte de Nueva España. Encabezó un motín y murió en 1533 en un enfrentamiento con los nativos.

18. Francisco de Ulloa fue un marino español que acompañó a Hernán Cortés en su tercer viaje por el mar del Sur. 
En 1542, Juan Rodríguez Cabrillo ${ }^{19}$ llegó hasta San Francisco y, en 1587, Pedro de Unamuno visitó la bahía del Morro, en California, en un viaje de regreso de Filipinas. Juan de Fuca llegó hasta Puget Sound en 1592 y atravesó el estrecho que lleva su nombre. Ya, en 1602, la expedición de Sebastián Vizcaíno recorrió las costas de California llegando hasta el actual estado de Oregón. El interés por explorar los territorios hacia Canadá y Alaska fue muy tardío, con la construcción de misiones en San Diego en 1767, en Monterey en 1770 y San Francisco en 1776, cuya bahía no se divisó desde el océano y solamente se descubrió con la expedición de Gaspar de Portolá ${ }^{20}$ en 1769. A partir de 1774 España intensificó la exploración de los territorios al norte de los actuales estados de Oregón y Washington, donde ya se estaban instalando los comerciantes de pieles rusos, a través de la Compañía Ruso-Americana, ${ }^{21}$ que ubicaron establecimientos más o menos permanentes, como Sitka, que se convertiría en la capital de la América rusa.

En 1774, el explorador español Juan José Pérez Hernández ${ }^{22}$ llegó hasta el sur de Alaska, donde años más tarde el explorador James Cook realizó estudios cartográficos de gran importancia, incluida la isla de Vancouver. Juan Francisco de la Bodega y Cuadra ${ }^{23}$ navegó a lo largo de las costas canadienses y de Alaska, donde estableció un asentamiento en Nutka, en la isla de Vancouver llegando hasta lo que hoy es Prince William Sound, ${ }^{24}$ dando nombre al cabo que lleva su nombre y negoció con George Vancouver la soberanía de los territorios que se disputaban con Gran Bretaña. En 1778 Esteban José

19. Juan Rodríguez Cabrillo (1498-1543) fue un marino y explorador español. En 1542 descubrió la Bahía de San Diego, a la que llamó San Miguel, y llegó a San Pedro, que es el puerto de Los Ángeles, Santa Mónica y descubrió las actuales islas de Santa Bárbara. En 1543 llegó al cabo Mendocino, en el norte de California.

20. Gaspar de Portolá Rovira (1716-1786) fue un militar y explorador español que fue nombrado gobernador de las Californias, entre 1767 y 1770 , y fundó San Diego y Monterey.

21. La Compañía Ruso-Americana, conocida por sus siglas RAK, fue la primera compañía mercantil rusa con la protección del zar. Fue fundada por Nikolai Rozanov en 1799.

22. Juan José Pérez Hernández (1725-1775) fue un navegante español que recorrió las costas de América del Norte hasta Alaska. En 1774 llegó a la isla de Nutka y dejó numerosos topónimos en la región, como el Cerro Nevado de Santa Rosalía, hoy monte Olympus, en el estado de Washington.

23. Juan Francisco de la Bodega y Cuadra (1743-1794) fue un marino que exploró la costa del Pacífico de América del Norte hasta Alaska en una expedición para localizar los asentamientos rusos, dando nombre a varios accidentes geográficos como el cabo que lleva su nombre. Recorrió la costa del estado de Washington y llegó a Sitka en Alaska en 1775.

24. Prince William Sound está situado en el golfo de Alaska, al este de la península de Kenai cuyo puerto es Valdez. En la zona están otras pequeñas islas como Cordova y Whittier. En 1793 Alexander Adreivich Baranov fundó el puerto de Voskresensk pero la venta de Alaska en 1867 borró su huella. 
Martínez viajando hacia el norte de la costa americana del Pacífico, se encontró con los rusos en Unalaska y en la isla de Kodiak, que también visitó Juan Francisco de la Bodega al año siguiente, en 1789, descubriendo la presencia de barcos británicos y de la nueva república de Estados Unidos de América. En 1791 Malaspina realizó importantes estudios cartográficos de la costa de Alaska. En 1792 el marino Dionisio Alcalá Galiano rodeó la actual isla de Vancouver, entre Estados Unidos de América y Canadá. España renunció a la soberanía de los territorios situados al norte de California por el Tratado de Adams-Onís, de 1819.

Las exploraciones españolas por el Pacífico comenzaron a mediados del siglo XVI y reúnen una larga lista de navegantes, exploradores y científicos. En 1567-1568 Álvaro de Mendaña de Neira llegó hasta las islas Salomón, partiendo desde Perú y en 1595 alcanzó las islas de Santa Cruz, donde murió, pero su expedición llegó hasta las islas Filipinas. Ya en el siglo XVII la expedición de Pedro Fernández de Quirós arribó a la isla de Vanuatu en 1606 y uno de sus navíos al mando de Luis Váez de Torres llegó hasta Nueva Guinea, avistando el norte de Australia y atravesó el estrecho que hoy lleva su nombre en su honor.

El Imperio español en el océano Pacífico no se vio amenazado por otras potencias excepto en contados episodios, fundamentalmente la larvada guerra con Portugal en Insulindia, las localizadas incursiones neerlandesas y, el episodio más importante, la ocupación de Manila por los británicos entre 1762 y 1764. Este último episodio fue consecuencia de la alianza del Tercer Pacto de Familia del rey Carlos III con Francia, enfrentada con Gran Bretaña en la Guerra de los Siete Años. La flota británica dirigida por William Draper y el vice-almirante Samuel Cornish arribó frente a Manila, que dirigieron un ultimátum al arzobispo Rojo, gobernador y capitán general de Filipinas. Como recoge Carlos Vila Miranda "la carta, firmada por Cornish y por Draper, comunicaba el estado de guerra existente entre la Gran Bretaña y España y presentaba su intimación formal exigiendo la capitulación y entrega de Manila" (Vila, 2007, p. 174). La ocupación duró solamente 20 meses abandonando Manila y Cavite la fuerza británico-india, en abril de 1764. La pretendida expansión mercantil británica con la Compañía Británica de las Indias Orientales quería utilizar Manila, que era una de las ciudades comerciales occidentales en el Pacífico, pero fue un fracaso.

Algunas acciones militares enfrentaron a España con otras potencias en el océano. La guerra del Pacífico de 1866 contra Chile, Bolivia, Ecuador y Perú no fue muy afortunada y pudieron haber provocado una confrontación 
con Estados Unidos de América y Gran Bretaña en el sur del Pacífico. ${ }^{25}$ Por otra parte España apoyó la aventura colonial de Francia en la Cochinchina sin ningún beneficio para España. En esa época la sucesión a la Corona de España tuvo efectos geopolíticos en el continente europeo pues la candidatura alemana de Leopoldo de Hohenzollern-Singmaringen para suceder en el trono a Isabel in fue el origen de la guerra franco prusiana, entre julio de 1870 y mayo de 1871. El rey Alfonso XII contrajo matrimonio con Mercedes de Orleáns, que falleció a los pocos meses, y en segundas nupcias con María Cristina de Habsburgo-Lorena, prima del emperador Francisco José I de Austria. Con el primer gobierno de la Restauración, presidido por Antonio Cánovas del Castillo, se puso fin a la guerra civil y se firmó la Paz de Zanjón en 1878, que supuso una tregua en la insurrección en Cuba.

\section{China: un imperio tutelado por las potencias coloniales}

El Imperio chino fue presa de las invasiones y las influencias de sus vecinos mongoles y rusos por tierra y, especialmente a partir del siglo XVIII fue objeto de agresiones y ocupaciones por la costa del océano Pacífico, con el objeto de abrir el país al comercio occidental. El Imperio mongol ya había iniciado la exportación a China del opio pero fueron los británicos quienes desarrollaron una política comercial triangular basada en el comercio del opio para poder financiar las importaciones de productos chinos. ${ }^{26}$ España había desarrollado un intenso tráfico comercial con el "Galeón de Manila" desde 1565 extendiendo su influencia hasta China y otros países asiáticos. La moneda de plata española "real de a ocho" o "dólar español" se convirtió en la moneda generalmente aceptada en todo el Pacífico. El emperador Daoguang prohibió el comercio del opio en China, en $1829,{ }^{27}$ lo que originaría la Primera Gue-

25. El almirante Casto Méndez Núñez dirigió la escuadra española en la guerra del Pacífico, entre 1864 y 1866 y atacó el puerto chileno de Valparaíso, después de amenazar a los navíos británicos y norteamericanos que se habían interpuesto ante la flota española. Bombardeó el puerto peruano de El Callao en 1866.

26. Los portugueses se habían establecido en el territorio chino de Macao. La "Compañía Británica de las Indias Orientales" y la "Compañía Neerlandesa de las Indias Orientales" traficaron con opio y su exportación a China.

27. Desde su llegada a Filipinas, los comerciantes españoles exportaban a China una mezcla de opio y tabaco, que después utilizaron neerlandeses y británicos. El comercio del opio generó grandes fortunas y el banco "Hong Kong \& Shangai Banking Corporation”, fundado en Hong Kong, en 1865, por el escocés Thomas Sutherland, tuvo su origen en el comercio del opio en China. Actualmente tiene su sede en Londres. 
rra del Opio entre Reino Unido y China durante el período 1839-1842. Una Segunda Guerra del Opio se produjo entre 1856 y 1860, con la participación de Francia y Reino Unido.

Al final de la primera guerra el Imperio chino tuvo que aceptar los términos del Tratado de Nankin, firmado el 29 de agosto de 1842, el primero de los llamados "tratados desiguales" impuestos por el Reino Unido a China, con importantes concesiones comerciales y forzando la cesión de la isla de Hong Kong, ${ }^{28}$ política que benefició a Portugal obteniendo de China la ampliación de su territorio de Macao. A la Segunda Guerra del Opio, de 1856 a 1860, se puso fin mediante el Tratado de Tianjin o Tiensin, de $1858,{ }^{29}$ al que inicialmente se opusieron los chinos, y la Convención de Pekín de 1860 firmada con el Imperio británico, Francia, el Imperio ruso y Estados Unidos de América, que ya aparecía en la esfera del Pacífico occidental. La situación de debilidad del gigante chino se acrecentó tras la derrota en la guerra de 1894-1895 contra Japón, con la pérdida de la península de Corea, la isla de Formosa y el archipiélago de las islas de los Pescadores, tras la firma del Tratado de Shimonoseki, en $1895 .^{30}$ Hay que recordar que España envió un destacamento a Pekín durante la guerra chino-japonesa de 1894-95 y ésta sería la última participación de fuerzas españolas en un conflicto en Asia

28. El Tratado de Nankin, firmado el 29 de agosto de 1842, a bordo del buque británico HMS Cornwallis anclado en el puerto de Nankin, entre el Imperio británico y el Imperio chino de la Dinastía Qing, puso fin a la primera guerra del opio. El artículo 3 del tratado reconoce la cesión a perpetuidad de la isla de Hong Kong: “...His Majesty the Emperor of China cedes to Her Majesty the Queen of Great Britain, \&c., the Island of Hong-Kong, to be possessed in perpetuity by Her Britannic Majesty, her heirs and successors, and to be governed by such laws and regulations as Her Majesty the Queen of Great Britain, \&c., shall see fit to direct". Traducción del autor: Su Majestad el emperador de China cede a su Majestad la reina de Gran Bretaña la isla de Hong Kong para ser poseída a perpetuidad por su Majestad británica, sus herederos y sucesores y para ser gobernada por las leyes y regulaciones que su Majestad la reina de Gran Bretaña crea convenientes aplicar (“Treaty between Her Majesty”, 1843 , p. 3597 y ss.).

29. Por el Tratado de Tiensin, el Imperio británico, Francia, el Imperio ruso y Estados Unidos de América obtuvieron la autorización para abrir legaciones diplomáticas en Pekín, la apertura al comercio de 11 puertos, el derecho de libre navegación para los buques de los vencedores, la libertad de movimiento para los extranjeros por el interior de China, la libertad religiosa e importantes indemnizaciones al Reino Unido y Francia. En el tratado firmado con Estados Unidos de América, que consta de 30 artículos, este país obtenía los mismos privilegios que China concedía a los demás países (Treaty de Of Tianjin, 1858).

30. El Tratado firmado el 17 de abril de 1895, además de importantes compensaciones económicas, ventajas comerciales y la pérdida territorial de la península de Corea, dio pie a un protectorado japonés que sería el germen de futuras hostilidades con el Imperio ruso. 
continental. ${ }^{31}$ En noviembre de 1897 el kaiser Otto von Bismarck envió una escuadra que ocupó el puerto de Qingdao con motivo del asesinato de dos misioneros alemanes. Más tarde una escuadra rusa ocupó Lushun, el Reino Unido ocupó Weihal y Francia obtuvo el arrendamiento de Zanjiang. ${ }^{32}$ En 1898 China y el Reino Unido firmaron una Segunda Convención de Pekín por la que China arrendaba al Reino Unido otros territorios e islas próximos a Hong Kong necesarios para su defensa ${ }^{33}$. Las concesiones territoriales al Imperio ruso en Asia central y costa del Pacífico, a Japón en la península de Corea y al Reino Unido en las costas despertó el odio hacia los extranjeros, provocando la "rebelión de Taiping" y la "rebelión de los Boxers".

La Dinastía manchú Qing logró el apoyo del grupo conocido como "boxers" y decidió enfrentarse con las potencias coloniales cuyos intereses económicos y comerciales estaban explotando los recursos naturales y realizando inversiones en infraestructura, especialmente ferroviaria, en el norte de China. El "levantamiento de los Boxers" contra los extranjeros comenzó en noviembre de 1899 y terminó en septiembre de 1901, dirigida en un principio contra la influencia extranjera en China, asesinaron a cristianos chinos y, en junio de 1900, se enfrentaron a las tropas de ocupación en ciudades como Tiensin y Pekín donde las embajadas de varios países occidentales fueron atacadas y aisladas. En agosto se organizó la "Alianza de las ocho naciones", formada por el Reino Unido, Francia, el Imperio ruso, el Imperio austro-húngaro, Italia, Estados Unidos de América, el Imperio alemán y Japón, para socorrer a los nacionales occidentales. Tras el asesinato del canciller japonés, Sugiyama, y del embajador del Imperio alemán, Von Ketteler, el gobierno chino declaró la guerra a los gobiernos de la Alianza. El 7 de septiembre de 1901, se firmó el Tratado de Xinchou, conocido como Tratado Bóxer entre la Dinastía Qing y los gobiernos del Imperio alemán, el Imperio austro-húngaro, Reino Unido,

31. El historiador Carlos Cólogan (2015, p. 11) reproduce una foto con la fuerza española, que lleva el título "Détachement espagnol venu à Pekín, hiver 1894-95 (guerre sino-japonaise)" [Destacamento español venido a Pekín, invierno 1894-95 (guerra chino-japonesa)].

32. Zanjiang está situada al nordeste de la península de Leizhzu y fue rebautizada por los franceses como Fort-Bayard, formó parte del territorio francés de Luang-Chu-Wan desde 1898 hasta 1945.

33. La Segunda Convención de Pekín fue firmada el 9 de junio de 1898 y otorgaba al Reino Unido el arrendamiento por 99 años. En 1984, China y Reino Unido firmaron la Declaración Conjunta Chino-Británica, por la que éste se comprometía a la devolución de todos los territorios el 1 de julio de 1997. 
Francia, Estados Unidos de América, el Imperio ruso, Japón, España, Italia, Países Bajos y Bélgica. ${ }^{34}$

Para España, que había sufrido la derrota en la guerra de 1898 contra Estados Unidos de América, la firma del Protocolo Bóxer fue el último éxito diplomático en Extremo Oriente ya que las negociaciones de las duras condiciones impuestas a China tuvieron lugar en el comedor de la embajada española en Pekín. En un principio hubo una gran oposición por parte de los representantes de los países de la Alianza pero finalmente fue aceptado el embajador español Bernardo J. de Cólogan y Cólogan para presidir las negociaciones pues era el decano del Cuerpo diplomático en la capital china. ${ }^{35}$ Como relata el propio embajador español Bernardo J. Cólogan: ${ }^{36}$

el artículo más traumático fue sin duda, el número seis que fijaba una indemnización de 450 millones de taeles (1.687.500.000 francos o 67.500.000 dólares), casi un tael por cada habitante del país, a pagar por el gobierno a las naciones ocupantes. (Cólogan, 2015, p. 188). ${ }^{37}$

Pero las consecuencias para el escenario geopolítico en el océano Pacífico fueron transcendentales. España no recibió prácticamente ninguna indemnización ya que no sufrió pérdidas humanas. La presencia de Estados Unidos en la región salió reforzada pues contaba con la ocupación de las antiguas colonias españolas en el Pacífico. El presidente estadounidense McKinley hizo uso por primera vez de las fuerzas armadas en el extranjero sin autorización del Congreso norteamericano contra un país soberano, política que continuó su sucesor Theodore Roosevelt.

34. El "Tratado Boxer" fue negociado por todas las partes involucradas en la embajada de España, bajo la dirección del embajador de España en Pekín, Bernardo de Cólogan y Cólogan ya que era el decano del cuerpo diplomático acreditado en Pekín y mantenía buenas relaciones con la emperatriz Ci Xi. Las negociaciones constan en el archivo $\mathrm{M}^{\circ}$ _EXTERIORES_TR,324,NEGOCIACIÓN 13: Nota de los representantes diplomáticos acreditados en China al gobierno chino sobre la revolución de los boxers (Cólogan, 2015).

35. En la película "55 Días en Pekín”, cuyo argumento está basado en el asedio de las legaciones diplomáticas en Pekin, el embajador español aparece con el nombre de Guzmán. La película fue dirigida en 1963 por Nicholas Ray e interpretada por Charlton Heston, Ava Gadner y David Niven y fue rodada en Las Rozas (España).

36. Reproducido por Carlos Cólogan Soriano en su libro, a quien agradezco la autorización de la alusión contenida en la documentación de su ascendiente Bernardo J. Cólogan y Cólogan.

37. El tipo de cambio aplicado era de 1 Haikouan tael = 3.055 marcos alemanes, 3.595 coronas austrohúngaras, 0.742 dólares oro, 3.750 francos, 1.407 yens, 1796 florines holandeses, 1.412 rublos y 0.3 s. libras esterlinas (Cólogan, 2015, p. 241). 
Las diferencias entre el Imperio ruso y Japón sobre las áreas de influencia en Manchuria y la península de Corea condujeron a la guerra entre ambas naciones en 1905, saliendo victorioso el Imperio del Sol naciente al aplastar la flota rusa del Pacífico en Port Arthur. Japón era reconocido como el nuevo poder hegemónico en el Extremo Oriente por lo que Reino Unido y Estados Unidos de América, temerosos de las ambiciones expansionistas japonesas en Asia y en el Pacífico, decidieron condonar las sanciones impuestas a China. Las ambiciones de los países coloniales occidentales y Japón se fundaban en la explotación de los enormes recursos naturales de China y en los inmensos beneficios que el mercado chino reportaba, además de las posibilidades de inversión en infraestructura de transporte, de las que dichas potencias disponían de la más moderna tecnología de la época. Eran conocidas la existencia de las minas de estaño, hierro, cobre y zinc en Yunnan y las grandes reservas de carbón.

\section{Un Imperio del Sol naciente en el océano Pacífico}

Cuando se descubrió la ruta del "tornaviaje” o viaje de regreso desde Filipinas hacia América se institucionalizó la ruta comercial y de transporte en general con el "Galeón de Manila" o "Nao de la China", estableciendo una corriente comercial entre ambas orillas del océano Pacífico desde 1571, siendo Manila la base de todas las operaciones. Había nacido la primera ruta comercial global comercial, económica y monetaria. China y Japón eran objetivos importantes en las relaciones exteriores de la monarquía hispana y, a partir del siglo XVII, este interés creció.

Uno de los galeones de Manila, el "San Francisco", en su ruta hacia Acapulco en 1609, naufragó cerca de las costas japonesas de Chiba, en la región de Tokio. El capitán del galeón, Rodrigo de Vivero y Aberrucia ${ }^{38}$ logró entrevistarse con Tokugawa Ieyasu logrando los españoles la firma de un acuerdo por el que se autorizaba a los navíos españoles a arribar a las costas japonesas y a instalar factorías occidentales con técnicos de Nueva España y, la gran

38. Rodrigo de Vivero y Aberrucia (1564-1636) oficial español, que fue nombrado gobernador de Filipinas, de forma interina en 1608. Era sobrino de Luís de Velasco, virrey de Nueva España. 
novedad, se organizaría el envío de una misión diplomática a Madrid. ${ }^{39}$ El franciscano Luís Sotelo logró que Tokugawa fuera enviado como embajador de la misión a Madrid. El monje Luís Sotelo solicitó al virrey de Nueva España, Luis de Velasco, el envío del explorador español Sebastián Vizcaíno como un embajador a Japón. Entre 1613 y 1620 Hasekura Tsunenaga fue el jefe de la misión que viajó a España, visitó Francia y llegó a Roma para visitar al Papa Pablo V. ${ }^{40}$ En España se entrevistó con el rey Felipe III, el 30 de enero de 1615, aunque rechazó la firma de un acuerdo con los japoneses por la persecución que sufrían los cristianos en aquel país. Hasekura no solo fue el primer embajador japonés que visitó Europa sino también América. ${ }^{41}$

En el siglo XIX acontecen dos hechos de gran importancia que influirían en la modernización de Japón, que era un país cerrado a las influencias extranjeras y con una estructura feudal dirigida por el shogunato de la familia Tokugawa. El primero es la desaparición del shogunato y el segundo fue la llegada de una flota de Estados Unidos al mando de Mathew C. Perry del que luego se hablará. Tras numerosas turbulencias y guerras internas, se inicia el período Meiji, cuando en enero de 1867 falleció el emperador Kómei y le sucedió el príncipe Mutsuhito, que contaba con 15 años, como nuevo emperador Meiji. La restauración del poder absoluto ponía fin a siete siglos de gobierno de los shogunes, convirtiéndose el emperador como símbolo de la unidad nacional. A principios de 1868 estalló una nueva guerra civil tras la rebelión

39. Rodrigo de Vivero y Aberrocia permaneció 9 meses en Japón y negoció un acuerdo en que se solicitaba el establecimiento de una base naval en el este de Japón, la expulsión de los neerlandeses, que tenían el monopolio comercial, y la libertad religiosa, a cambio de facilitar a Japón el comercio transpacífico y de tecnología moderna para la minería de la plata. Fue el inicio de las relaciones entre Japón y el Imperio español.

40. Hasekura Rokuemon Tsunenaga (1571-1622) samurai japonés que emprendió el viaje a España a través del océano Pacífico, Nueva España y Cuba. Partió de Japón el 28 de octubre de 1613 y llegó a España el 20 de diciembre de 1614. Arribó a la península Ibérica a través del río Guadalquivir, llegando a la localidad de Coria del Río, trasladándose por tierra hasta Madrid. Después, en su viaje hacia Roma se trasladó a Barcelona, recalando en el sur de Francia. En 1619 regresó a Japón haciendo la misma ruta a través de Nueva España, por lo que Hasekura es el primer japonés que dirigió una misión diplomática a Europa. Algunos miembros de la misión japonesa se quedaron en la ciudad española de Coria del Río y, actualmente, sus descendientes llevan el apellido de "Japón”. Hasekura fue bautizado en la religión católica con el nombre de Felipe Francisco Haskura (Frédéric, 2002, pp. 293-294).

41. La publicación “Japan Times”, de 11 de diciembre de 2003, publicó una información sobre este poco conocido hecho que representó la apertura de Japón y el inicio de las relaciones diplomáticas con España y otros países europeos. Después Japón se aislaría de nuevo. 
de los samurais leales al shogunato y tras la guerra, la ciudad de Edo adoptó el nombre de Tokio a donde se trasladó la capital del país desde la antigua Kioto.

El derrotado ejército del shogunato se refugió en la isla de Hokkaido (Yeso), donde establecieron un gobierno propio y declararon la "República de Ezo", en diciembre de 1868, intentando el reconocimiento internacional. Sin éxito en el campo de batalla y en el campo diplomático, el gobierno del shogunato Tokugawa sucumbió completamente ante la armada imperial que puso fin a la corta República de Ezo en marzo de 1869. Desde el final de la guerra el emperador controló y unificó Japón desde la isla de Honshu (Hondo). Con el período Meiji (1868-1912) se inicia la industrialización del país y la modernización de su ejército, siguiendo el modelo alemán, y de la armada, a semejanza de la Royal Navy, lo que convirtió a Japón en una gran potencia económica y militar en pocos años. Se adoptaron reformas del sistema educativo y se modernizaron las instituciones financieras de acuerdo al modelo estadounidense, convirtiendo a Japón en el primer país industrializado de Asia y un país económicamente muy desarrollado. La concentración del capital financiero en una reducida burguesía y la formación de grandes monopolios sentaron las bases de la futura potencia hegemónica en Asia.

Con la llegada de la paz interna, Japón revivió su antiguo interés en la península de Corea, separada solamente por un estrecho, y donde la ciudad de Pusan se divisaba desde las costas japonesas de Tsu. Japón consideraba a Corea un territorio estratégico para su defensa y donde Japón ya había obtenido el derecho de comercio con los puertos coreanos desde 1876. Como se ha descrito anteriormente, el deterioro de las relaciones chino-japonesas tras la presencia de tropas chinas en Corea desencadenó la Primera Guerra Chino-Japonesa (1894-1895) que terminó con la victoria nipona. El Tratado de Simonoseki, que puso fin a la guerra, reconocía la independencia de Corea, el derecho de navegación comercial de Japón por el río Yangtse, la apertura de China a las inversiones japonesas y la cesión a Japón de las islas de Taiwán y de Pescadores y la península de Liadong, que fue devuelta a China por las presiones de Rusia, Francia y Alemania. Japón apoyó a las tropas occidentales en China en 1900 durante la "rebelión de los Bóxers". La participación de Japón en las acciones de los países coloniales occidentales facilitó que Japón se convirtiera en la $5^{\mathrm{a}}$ potencia mundial del siglo $\mathrm{XX}$, con las consecuencias de todos conocidas. 


\section{La presencia de Estados Unidos en el océano Pacífico}

En 1805, la primera expedición estadounidense de Lewis y Clark también llegó a las costas del Pacífico ${ }^{42}$ en una empresa apoyada por el presidente Thomas Jefferson y el Congreso de Estados Unidos de América, en el intento de búsqueda de rutas navegables que hicieran posible las relaciones comerciales con la orilla del Pacífico. El contexto político era muy delicado pues el territorio de Luisiana pertenecía a España por lo que el gobierno de Estados Unidos de América contactó con el embajador español Carlos Martínez de Irujo, que era responsable del territorio quien manifestó al gobierno estadounidense que España no aceptaría tales incursiones en el territorio. Desde la perspectiva geopolítica, el océano Pacífico fue periferia desde su conocimiento por los europeos en el siglo XVI, hasta la desaparición del Shogunato en Japón y la llegada del comodoro Matthew C. Perry ${ }^{43}$ al mando de una flota de los Estados Unidos de América a aquel país que permitió la apertura de ese territorio al mundo occidental mediante el Tratado de Kanagawa de 1854. Los contactos con portugueses, neerlandeses y españoles fueron muy limitados pues, como hemos mencionado, España y Japón tenían relaciones muy estrechas y España facilitó la primera misión japonesa a América y Europa.

En efecto en 1852 el presidente estadounidense Millard Fillmore ${ }^{44}$ encomendó al Comodoro Matthew $C$. Perry la misión de dirigirse a Japón para que este país abriera sus puertos al comercio estadounidense. Las instrucciones del presidente eran claras y Perry debía utilizar la fuerza en caso de oposición de Japón a las pretensiones del gobierno estadounidense, es lo que se conoce en geopolítica como "diplomacia de las cañoneras" ya utilizada ampliamente por algunas potencias europeas y, particularmente, Inglaterra. Cuatro años antes los estadounidenses habían logrado llegar a las costas norteamericanas

42. El presidente de Estados Unidos Thomas Jefferson apoyó de forma decidida la primera expedición hacia las costas del océano Pacífico, dirigida por Meriwether Lewis y William Clark entre 1804 y 1806, alcanzando el océano en 1805.

43. Matthew Calbraith Perry (1794-1858) fue comodoro de la armada de Estados Unidos, nombrado en 1840, desempeñó un papel muy importante en la apertura de Japón al mundo occidental. Participó en acciones navales durante la guerra de 1812 y la guerra mexicano-estadounidense de 1846-1848. Representó un papel fundamental en la formación de oficiales de la marina a través de la Academia Naval de Estados Unidos. Influyó en la modernización de la armada y fue un gran impulsor de la navegación de buques de vapor, siendo considerado el "padre de la armada de buques de vapor de Estados Unidos".

44. Millard Fillmore fue el $13^{\circ}$ presidente de Estados Unidos entre 1850 y 1853. 
del océano Pacífico, después de los dos años de guerra contra México, a quien había desposeído de los inmensos territorios por el Tratado de Guadalupe Hidalgo, de 2 de febrero de $1848 .{ }^{45}$

El comodoro Perry partió con su flota de Norfolk, en Virginia, el 24 de noviembre de 1852, a bordo de la fragata Mississippi. Las experiencias de la misión fueron descritas en la Narrative of the Expedition of An American Squadron. The China Seas and Japan ${ }^{46}$ donde relata el itinerario de la flota pasando por Canarias, Madera, Santa Elena, Ciudad del Cabo, Mauricio, Ceilán, Singapur, Macao y arribando a Hong-Kong en abril de 1853. A mediados de mayo llegó a Naha, en la actual isla de Okinawa y solicitó audiencia al rey Sho-Tai de quien le prometió la apertura de su territorio al comercio con Estados Unidos. Sin embargo, el 8 de julio de 1853, tras llegar a las islas Ogasawara y Uraga, en la bahía de Tokio, le pidieron que continuara hacia Nagasaki, único puerto que estaba abierto al comercio con los extranjeros desde la llegada de los neerlandeses. Perry presentó la carta del presidente estadounidense al consejero jefe del shogunato Tokugawa, Abe Masahiro, ${ }^{47}$ y prosiguió su ruta hacia la actual Yokosuka, el 14 de julio de 1853, y después regresó a Hong-Kong.

Tras las noticias de la primera "guerra del opio", regresó la escuadra de Perry reforzada con navíos británicos, franceses, neerlandeses y rusos, en febrero de 1854, para presionar al Shogunato, que no pudo oponerse a la "diplomacia de las cañoneras" y el 31 de marzo de 1854 firmó el Tratado de

45. El nombre oficial es "Tratado de Paz, Amistad, Límites y Arreglo Definitivo entre los Estados Unidos Mexicanos y los Estados Unidos de América", aunque parezca un eufemismo. Con las pérdidas territoriales, la frontera entre ambos países se estableció en el río Bravo. Estados Unidos pagó al gobierno mexicano la suma de 15 millones de dólares, práctica que sería habitual en las apropiaciones territoriales del gigante estadounidense, dando la apariencia de una transacción comercial que encubre la verdadera realidad.

46. Como comodoro de la Marina de Estados Unidos se hizo famoso por la expedición que el presidente Millard Fillmore le encomendó, con el propósito de abrir Japón al comercio con Occidente. Las experiencias de la expedición quedaron reflejadas en su obra Narrative of the Expedition of An American Squadron. The China Seas and Japan. Performed in the years 1852, 1853 and 1854 under the command of Commodore M.C. Perry, escrita por Francis L. Hawks en 1856.

47. Abe Masahiro (1819-1857) consejero jefe superior del Shogunato Tokugawa y partidario de la apertura de su país al comercio con los países occidentales. En 1852, informó al Shogun sobre la política exterior de los países occidentales y del inicio de la primera "guerra del opio" contra China. El Tratado de Kanagawa con Estados Unidos de América fue el preludio de la apertura de Japón al comercio con otras potencias europeas. Abe Masahiro potenció la formación de un ejército moderno y una administración eficaz y racional. 
Kanagawa. ${ }^{48}$ Japón se abría al comercio con Estados Unidos de América, que se vio beneficiado del establecimiento de carboneras para sus buques de vapor. Posteriormente, Reino Unido, los Países Bajos y Rusia firmaron convenios similares. Antes de regresar Perry recorrió la costa de la isla de Hokaido, al norte del archipiélago, visitando Hakodate y Shimoda, que serían abiertas al comercio estadounidense por el tratado firmado. Cuando Perry visitó la isla de Formosa, actual Taiwán, analizó su posición estratégica y la comparó con la plataforma que supuso Cuba para que España conquistara casi todo el continente americano pero no fue apoyado por su gobierno.

El Tratado de Kanagawa era un convenio de los varios que Estados Unidos de América firmó con otros países, incluido el Tratado de París de 1898 que supuso la pérdida de las últimas más importantes colonias españolas en América, Asia y Oceanía, y que se calificaron en el argot diplomático como "tratados desiguales" ya que eran auténticas imposiciones y no existía la capacidad de negociación, a pesar de que se asegura que "habrá una paz perfecta, permanente y universal, y una amistad sincera y cordial entre los Estados Unidos de América, por una parte, y el Imperio de Japón, por otra parte..."49. El Tratado de Kanagawa consta de 12 artículos y está encabezado por un eufemismo que define la política exterior de Estados Unidos de América frente a sus competidores o adversarios. El Tratado obliga a Japón a abrir los puertos de Shimoda y Hakodate a los navíos estadounidenses y a facilitarles el avituallamiento necesario y la asistencia a estos buques en caso de necesidad, la obligación de aceptar el pago en moneda de oro y plata, el otorgamiento

48. El Tratado fue firmado en Kanagawa, próxima a la actual Yokohama, por el propio Matthew C. Perry, como plenipotenciario del gobierno de Estados Unidos, y por Hayashi Akira, como representante imperial.

49. El texto original: "There shall be a perfect, permanent, and universal peace and a sincere and cordial amity between the United States of America on the one part, and the Empire of Japan on the other part..." (“Empire of Japan Treaty”, 1854, art. I). 
de la cláusula de la nación más favorecida y el nombramiento de cónsules o agentes por el gobierno estadounidense. ${ }^{50}$

A mediados el siglo XIX Estados Unidos de América estaba despegando como una potencia intercontinental, mientras que el Reino Unido seguía siendo una potencia marítima. Ambos países tenían interés en la construcción de un canal interoceánico en América Central, donde el Reino Unido tenía un asentamiento en Belice y pretendía ampliar su área de influencia incluyendo la Costa de los Mosquitos, que el gobierno estadounidense observaba con desconfianza, a pesar de que éste había firmado el Tratado Mallarino-Bidlack, que le permitía la construcción de un canal interoceánico en Panamá. El 19 de abril de 1850, Estados Unidos de América y Reino Unido firmaron el Tratado Clayton-Bulwer ${ }^{51}$ que imponía la neutralidad de ambos países sobre el futuro canal. El posterior Tratado Hay-Pauncefote ${ }^{52}$ firmado en 1901 anuló el Tratado existente de 1850 y reconocía a Estados Unidos de América el mejor derecho a construir el canal interoceánico, con la condición que fuera una vía de libre tránsito para los buques de todas las naciones. Los intereses geopolíticos

50. El Tratado dice expresamente que "The port of Shimoda [in Yedo harbor], in the principality of Idzu, and the port of Hakodade, in the principality of Matsmai [Hokkaido], are granted by the Japanese as ports for the reception of American ships, ..." (art $\left.{ }^{\mathrm{o}} \mathrm{II}\right)$ - Traducción del autor: El puerto de Shimoda [en el puerto de Yedo], en el principado de Idzu, y el puerto de Hakodade, en el principado de Matsmai [Hokkaido], son otorgados por los japoneses como puertos para la recepción de barcos estadounidenses; "Whenever ships of the United States are thrown or wrecked on the coast of Japan, the Japanese vessels will assist them, and carry their crews to Shimoda, or Hakodade, ..." (art ${ }^{\circ}$ III) - Trad.: Cuando los barcos de Estados Unidos encallen o naufraguen en las costas de Japón, los navíos japoneses les ayudarán y transportarán a sus tripulaciones a Shimoda, o Hakodade..., ; “... ships of the United States resorting to the ports open to them shall be permitted to exchange gold and silver coin and articles of goods for other articles of goods, ... (art ${ }^{\circ}$ VII) - Trad.: los buques de los Estados Unidos que arriben a los puertos abiertos a ellos podrán intercambiar monedas de oro y plata y mercancías por otras; "...If at any future day the Government of Japan shall grant to any other nation or nations privileges and advantages which are not herein granted to the United States and the citizens thereof, that these same privileges and advantages shall be granted likewise to the United States and to the citizens thereof..." ( $\mathrm{art}^{\mathrm{o}} \mathrm{IX}$ ) - Trad.: Si en el futuro el Gobierno de Japón otorgará a cualquier otra nación o naciones privilegios y ventajas que no se otorguen aquí a los Estados Unidos y a sus ciudadanos, estos mismos privilegios y ventajas se otorgarán igualmente a Estados Unidos y sus ciudadanos...; "There shall be appointed, by the Government of the United States, Consuls or Agents to reside in Shimoda..." (art ${ }^{\circ} \mathrm{XI}$ ) - Trad.: Serán nombrados, por el Gobierno de los Estados Unidos, Cónsules o Agentes con residencia en Shimoda." ("Empire of Japan Treaty”, 1854).

51. El Tratado fue firmado por el secretario de Estado estadounidense, John Middleton Cayton, y el ministro plenipotenciario británico Henry Lytton Bulwer, denominándose Tratado ClaytonBulwer.

52. El Tratado Hay-Pauncefote fue firmado por el secretario de Estado de Estados Unidos de América, John Milton Hay, y el embajador británico en Washington, Lord Pauncefote. 
de ambas naciones dieron valor a la ruta que se abriría a través del canal de Panamá acercando los océanos Pacífico y Atlántico.

Los intereses estadounidenses impulsaron al Congreso de Estados Unidos de América a adoptar disposiciones que pueden ser calificadas de absurdas en el derecho internacional, como la Guano Islands Act, que fue aprobada por el Congreso el 18 de agosto de 1856 autorizando a los ciudadanos de Estados Unidos de América a ocupar islas, rocas o cayos donde se descubran depósitos de guano y no estén sometidas a la jurisdicción de otros países, y facultaba al presidente estadounidense para que utilice las fuerzas armadas en defensa de los intereses de sus nacionales y poder reclamar así la pertenencia a los Estados Unidos de América. Resulta absurda la legislación que establece:

Que cuando un ciudadano o ciudadanos de los Estados Unidos pueden haber descubierto, o descubrirán más adelante, un depósito de guano en cualquier isla, roca o cayo que no se encuentre dentro de la jurisdicción legal de ningún otro gobierno, y que no estén ocupados por ciudadanos de otro país, tomarán posesión pacífica de los mismos, y ocuparán dicha isla, roca o cayo y, a discreción del Presidente de los Estados Unidos, pueden ser considerados como pertenecientes a los Estados Unidos (“Guano Islands”, 1856).

El carácter imperialista de tan absurda legislación se desprende de lo establecido en la Sección 5: "Se autoriza al Presidente de los Estados Unidos, a emplear las fuerzas terrestres y navales de los Estados Unidos para proteger los derechos de dicho descubridor o descubridores..." 53

Y con base en la aplicación de la Guano Islands Act, Estados Unidos ha reclamado numerosos territorios isleños, atolones o corales situados en el océano Pacífico. Entre ellos, se pueden citar la Baker Island, atolón deshabitado situado a 3,090 kilómetros de Hawai y la Howland Island, una isla de coral deshabitada a 3,100 kilómetros de Hawai, ambas al sudoeste de dicho estado. Otros territorios son la Jarvis Island, isla de coral deshabitada, si-

53. La Guano Islands Act fue adoptada por el Congreso estadounidense el 18 de agosto de 1856. Su redacción es muy significativa pues se dice: “..., That when any citizen or citizens of the United States may have discovered, or shall hereafter discover, a deposit of guano on any island, rock, or key not within the lawful jurisdiction of any other government, and not occupied by the citizens of any other government, and shall take peaceable possession thereof, and occupy the same, said island, rock, or key may, at the discretion of the President of the United States, be considered as appertaining to the United States..." "Sec. 5 ... That the President of the United States is hereby authorized, at his discretion, to employ the land and naval forces of the United States to protect the rights of the said discoverer or discoverers..." ("Guano Islands", 1856). 
tuada entre Hawai y las Islas Cook; el atolón Johnston o Kalama, territorio administrado por el U.S. Fish and Wildlife Service; el Kingman Reef, arrecife deshabitado situado entre Hawai y la American Samoa (Samoa Americana); el atolón Midway ${ }^{54}$ que es territorio estadounidense situado entre Asia y América del Norte, en el grupo de las islas Hawai pero que no forma parte del Estado de Hawai, siendo la Sand Island la isla más importante y la única poblada; y las Swains Islands que es parte de la American Samoa, en la cadena de islotes de Tokelau y es una propiedad privada. Como se puede observar, no existían argumentos que no pudieran ser utilizados para la defensa de los intereses geopolíticos estadounidenses.

\section{Fin del ciclo geopolítico en el océano Pacífico: la transición}

El 25 de noviembre de 1885 falleció el rey Alfonso XII, quedando como Regente la reina María Cristina de Austria que estaba embarazada. El día 17 nació Alfonso XIII, quien heredó la Corona como hijo póstumo. En 1895, en Cuba nuevamente estalló la sublevación, dirigida por José Martí, Máximo Gómez y Antonio Maceo que luchaban por la independencia. Tanto el general Martínez Campos como el general Valeriano Weyler no tuvieron éxito en sofocar la rebelión, ayudada por los Estados Unidos. En Filipinas también se estaban produciendo sublevaciones contra la política del general Camilo García de Polavieja, experimentado militar que había participado en las guerras carlistas, en Marruecos y en Cuba, pero que no supo resolver el conflicto. Nombrado Gobernador general y capitán general del ejército español en las islas Filipinas mandó fusilar al intelectual nacionalista José Rizal, ${ }^{55}$ lo que abrió heridas con los filipinos que tardarían muchos años en cicatrizar.

54. La Batalla de Midway durante la II Guerra mundial tuvo lugar en junio de 1942 y fue el punto de inflexión en la guerra, que condujo a la derrota de Japón. Hasta 1993 fue la base de la Naval Air Facility Midway Island.

55. José Protacio Mercado Rizal nació el 19 de junio de 1861 en Calambá, provincia de Laguna, Filipinas, con mestizaje chino, malayo y español. Estudió en el Ateneo Municipal de Manila y en la Universidad de Santo Tomás. Aunque estudió Filosofía y Letras, completó su formación universitaria como oftalmólogo en España estudiando en la Universidad Central de Madrid donde se doctoró. Escribió obras como Noli me tangere, El filibusterismo y el poema Mi último adiós. Fue partidario de que Filipinas fuera una provincia española y no una colonia, con representación en las Cortes, reconociendo la igualdad entre españoles y nativos. Perteneció a movimientos independentistas y fue acusado de sedición. Murió fusilado el 31 de diciembre de 1896. 
España había dejado de ejercer una política geopolítica en el océano Pacífico pero no le inquietaba la amenaza de otras potencias. Como casi siempre sucedía, la falta de población hispana, la prioridad religiosa de evangelización y la miopía geopolítica y neoeconómica de los monarcas españoles, junto con la desidia de sus políticos, abandonaron la efectiva ocupación de muchos dominios. En 1852 el coronel Coello comunicó al gobierno español la importancia para los intereses comerciales de los territorios entre Filipinas, Nueva Guinea y América pero no fue escuchado. En 1870 el Pacífico estaba aun virgen del reparto colonial de la época imperialista y británicos, estadounidenses y alemanes mostraban interés en las islas de la Micronesia, aun dominios teóricos españoles. La presencia de Alemania en aquel océano se remonta a 1870 cuando empresas comerciales alemanas establecieron factorías en el norte de Nueva Guinea, merodearon por las islas Carolinas ${ }^{56}$ y llegaron al actual archipiélago de las islas Bismarck ${ }^{57}$ en 1872.

Ya en 1884 Alemania, y también el Reino Unido, pusieron en cuestión la soberanía española de los territorios de Joló y el norte de Borneo adyacentes a las islas Filipinas. En agosto de 1885, el embajador alemán en Madrid, el conde Solms-Sonnewalde comunicó al gobierno español la pretensión de Alemania de ocupar las islas Carolinas por no ejercer la soberanía el estado español. Posteriormente, el representante de España, Butron, logró el reconocimiento de la soberanía en pactos con los reyes de Koror y Artingal. Una flotilla alemana, con el cañonero Iltis, había llegado a Puerto Tomil, en el archipiélago español y el incidente entre España y Alemania se solventó por un laudo del Papa de 17 de diciembre de 1885, que reconocía la soberanía a España. Alemania obtuvo algunas concesiones comerciales y de pesca y una estación carbonera y naval, además de las islas Marshall. España actuó de forma negligente y con desidia en las islas Carolinas, Palaos y otras dependencias de la Micronesia española,

56. Las islas Carolinas fueron descubiertas por Alonso de Salazar y Diego de Saavedra, en 1526, y Álvaro de Saavedra tomó posesión de algunas islas. Francisco de Lezcano, a su llegada a Yap, las bautizó islas Carolinas, en honor a Carlos II, incluyendo las islas Palaos y las islas Marshall. Las Carolinas fueron ocupadas por Japón en la I Guerra Mundial y desde 1920 en base al mandato de la Sociedad de Naciones. Después de la II Guerra Mundial quedaron bajo el control de la ONU y fueron administradas por Estados Unidos, declarándose independientes como Estados Federados de Micronesia y República de Palaos, respectivamente, en 1994.

57. Las islas Bismarck es un archipiélago situado al nordeste de Nueva Guinea y lleva su nombre en honor al canciller alemán Otto von Bismarck. El primer occidental que llegó al archipiélago fue el neerlandés Willem Schouten en 1616, sin que ningún país reclamara su soberanía hasta que Alemania las incluyó en la Nueva Guinea Alemana, en 1884. 
sin que hubiera tomado posesión formal y efectiva de dichos territorios, hasta la adopción del Real Decreto de 19 de febrero de $1886 .{ }^{58}$ En la exposición de motivos de dicho Decreto se dice expresamente que:

La Nación española se ha comprometido á establecer en los mencionados Archipiélagos una administración que represente su Autoridad y que de hecho y constantemente la haga efectiva, cosa que el Gobierno de V. M. desea realizar, no tanto por ceder á la santidad de lo pactado, como porque á ello le obligaban los antecedentes y las gloriosas páginas de nuestra historia colonia (Gaceta de Madrid, 1886, p. 524).

El 15 de febrero de 1898 se produjo una explosión interna en el acorazado estadounidense Maine, que se encontraba atracado en el puerto de La Habana, y dio pie a que el gobierno del presidente William Mackinley declarara la guerra a España. Estados Unidos de América buscaba una ocasión para poder apoderarse de la isla, habiendo hecho varias ofertas económicas que fueron rechazadas por el gobierno de Madrid. Los intereses geopolíticos de los Estados Unidos chocaban con el Imperio colonial español en el Caribe y en Extremo Oriente, en la ruta de China y Japón. El importante valor estratégico de las colonias residuales españolas en América, el Pacífico y Extremo Oriente junto con la debilidad de la metrópoli, fueron suficientemente atractivos para el nuevo "centro geopolítico" que estaba surgiendo en América, área que había sido periferia en el sistema mundo de los siglos anteriores. Era la primera guerra en la que Estados Unidos de América participaba lejos de sus fronteras. Fue la primera guerra cubierta por los medios de comunicación que también azuzaron su estallido mediante campañas de propaganda nacionalista, como la organizada por William Randolph Hearst. ${ }^{59}$

58. Tras los incidentes con el Imperio alemán, el ministro español de Ultramar Germán Gamazo, adoptó el Real Decreto de 19 de febrero de 1886, que en su artículo $1^{\circ}$ dice que "Para el régimen y administración de las islas denominadas Carolinas y Palaos se establecerán dos Gobiernos políticos, uno en la región oriental y otro en la occidental, bajo la dependencia del Gobierno general de las Islas Filipinas. El Gobernador general fijará la residencia de los Gobiernos, teniendo en cuenta los medios de comunicación y el mejor servicio". (Gaceta de Madrid, 1886, p. 524).

59. Dice Lenin: "En los Estados Unidos, la guerra imperialista de 1898 contra España provocó la oposición de los 'antiimperialistas', los últimos mohicanos de la democracia burguesa, que calificaban de 'criminal' dicha guerra, consideraban anticonstitucional la anexión de tierras ajenas, denunciaban como un 'engaño de chovinistas' la actitud hacia Aguinaldo, el jefe de los indígenas filipinos (después de prometerles la libertad de su país desembarcaron tropas norteamericanas y se anexionaron las Filipinas), y citaban las palabras de Lincoln: 'Cuando el blanco se gobierna a sí mismo, esto es autonomía; cuando se gobierna y al mismo tiempo gobierna a otros, no es ya autonomía, esto es despotismo' (Patouillet, 1904, p. 272 en Lenin, 1917). 
Siendo capitán general de Filipinas el general Basilio Agustín y Dávila, que sustituyó a Fernando Primo de Rivera, el 1 de mayo de 1898 la flota norteamericana del almirante George Dewey destruyó la escuadra española, al mando del contralmirante Patricio Montojo, en el puerto de Cavite, mientras la del almirante William T. Sampson hacía lo mismo el 3 de julio al forzar a la armada española la salida del puerto de Santiago de Cuba, al mando del almirante Pascual Cervera, que cometió errores básicos de estrategia militar. La falta de visión de Cervera motivó el rechazo de las propuestas de los capitanes Fernando Villaamil y Joaquín Bustamante para atacar los puertos de la costa este estadounidense en una maniobra de distracción y diversificación de fuerzas navales. El 25 de julio el general Nelson A. Miles ocupó la isla de Puerto Rico, que no había intervenido en el conflicto. España intentó llegar a un acuerdo con el gobierno estadounidense a través del embajador francés en Washington, Jules Cambon, pero no tuvo éxito.

Las consecuencias de la guerra fueron desastrosas para España, que firmó el Tratado de París el 10 de diciembre de 1898 (ver figura 1), ${ }^{60}$ por la que se acordó la independencia de Cuba y la entrega a Estados Unidos de las posesiones de Filipinas, Guam y Puerto Rico. El Tratado de París, ratificado el 19 de marzo de 1899, que oficialmente se denomina "Tratado de paz entre España y los Estados Unidos de América", fue un tratado incondicional y consta de 17 artículos, de los cuales los más relevantes son los que se refieren a que "España renuncia todo derecho de soberanía y propiedad sobre Cuba" (artículo I), a "la entrega a los Estados Unidos la isla de Puerto Rico y las demás, que están ahora bajo su soberanía en las Indias Occidentales, y la isla de Guam, en el archipiélago de las Marianas o Ladrones" (artículo II), a que "España cede a los Estados Unidos el archipiélago conocido por las Islas Filipinas, que comprende las islas situadas dentro de las líneas siguientes". Precisamente esta descripción dará lugar a que éste artículo se complete con el "Tratado de cesión a los Estados Unidos de las islas de Cagayán, Joló y Sibutú y demás pertenecientes al archipiélago filipino”, firmado

60. La Reina Regente de España nombró plenipotenciarios a Don Eugenio Montero Rios, presidente del Senado, Don Buenaventura de Abarzuza, senador del Reino, Don José de Garnica, diputado a Cortes, magistrado del Tribunal Supremo, Don Wenceslao Ramírez de Villa-Urrutia, enviado extraordinario y ministro plenipotenciario en Bruselas y Don Rafael Cerero, general de división. Y por el presidente de los Estados Unidos de América a William R. Day, Cushman K. Davis, William P. Frye, George Gray, y Whitelaw Reid. 
en Washington el 7 de noviembre del año $1900 .{ }^{61}$ El artículo III al final de su redacción establece que "los Estados Unidos pagarán a España la suma de veinte millones de dólares (\$20.000.000) dentro de los tres meses después del canje de ratificaciones del presente Tratado".

Además, el Tratado reconoce temporalmente el derecho a la no discriminación comercial estableciendo que "los Estados Unidos durante el término de diez años... admitirán en los puertos de las Islas Filipinas los buques y las mercancías españoles, bajo las mismas condiciones que los buques y mercancías de los Estados Unidos" (artículo IV). La repatriación de los militares prisioneros y la evacuación de los territorios cedidos están contempladas en el artículo V pero "el término dentro del cual será completada la evacuación de las Islas Filipinas y la de Guam, será fijado por ambos gobiernos". Y “España y los Estados Unidos de América renuncian mutuamente por el presente tratado, a toda reclamación de indemnización nacional o privada de cualquier género de un Gobierno contra el otro, o de sus súbditos o ciudadanos contra el otro Gobierno", conforme al artículo VII, aunque dice al final que "Los Estados Unidos juzgarán y resolverán las reclamaciones de sus ciudadanos contra España, a que renuncia en este Artículo". Y el artículo IX reconoce los derechos de los españoles a su residencia y propiedad, cuando dice, entre otras cosas, que "Los súbditos españoles, naturales de la Península, residentes en el territorio cuya soberanía España renuncia o cede por el presente Tratado, podrán permanecer en dicho territorio o marcharse de él, conservando, en uno u otro caso, todos sus derechos de propiedad, con inclusión del derecho de vender o disponer de tal propiedad o de sus productos; y además tendrán el derecho de ejercer su industria, comercio o profesión sujetándose a este respecto a las leyes que sean aplicables a los demás extranjeros".

Curiosamente el gobierno estadounidense adoptó una decisión estratégica durante la negociación del Tratado de París al incluir en el artículo III solamente aquellos territorios que pudieran suponer plataformas útiles en el cinturón geopolítico que estaba desarrollando para el control del norte del océano Pacífico, ante el despertar de eventuales potencias, como eran Japón y el Imperio ruso, que muy pronto se enfrentarían en la guerra rusojaponesa de 1905. Estados Unidos de América no tenía nada que temer del

61. El Tratado, que consta de un artículo único, fue firmado en Washington por José Brunetti y Ganoso, duque de Arcos y por John Milton Hay, secretario de Estado estadounidense. Fue ratificado por la Reina Regente de España, María Cristina Habsburgo-Lorena y por el presidente William Mckinley. (Gaceta de Madrid, 1901, p. 983). 


\section{Figura 1}

Firma del Tratado de París

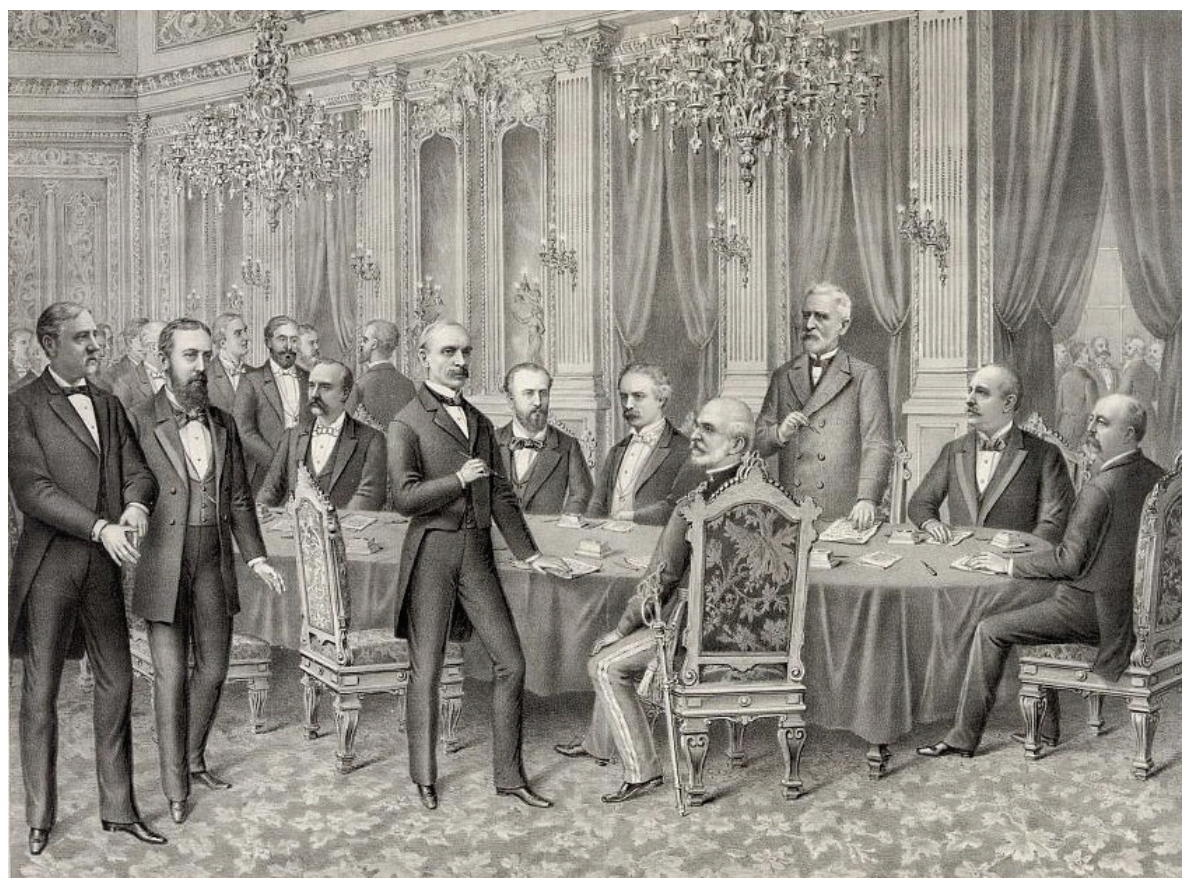

Fuente: Encyclopædia Britannica (1898).

Reino Unido que controlaba el paso del estrecho de Malaca y Singapur, con la Commonwealth que incluía Australia y Nueva Zelanda. Tanto Francia como Alemania no representaban ninguna amenaza para el control del océano y sus territorios ribereños, y China era un gigante durmiente con zonas de ocupación de las potencias coloniales, Japón, Reino Unido, Francia, Rusia, Portugal y Alemania. ${ }^{62}$ El Tratado de París fue el resultado de una imposición del vencedor de la guerra hispano-estadounidense que, paradójicamente, se inició para la defensa de los independentistas cubanos y filipinos pero ninguno de los dos territorios estuvieron representados en la firma del tratado.

62. Reino Unido tenía zonas de influencia en Hong-Kong y Weihawei, Francia en Luang-Cheu-Waa y la proximidad de la Indochina francesa, Alemania en Tsingtau y Portugal en Macao. 
Los archipiélagos de las islas Carolinas, Palaos, y Marshall fueron vendidas por España a Alemania al año siguiente, por 25 millones de pesetas, mediante el tratado hispano alemán firmado por Francisco Silvela y el príncipe alemán Chlodwig zu Hohenlohe y rubricado el 12 de febrero de 1899, que se publicaría en la Gaceta de Madrid el 24 de junio del mismo año, como "Ley autorizando al Gobierno para ceder al Imperio de Alemania las islas Carolinas con las Palaos y las Marianas, excepto Guam". La ley se publica en nombre del rey Alfonso XIII, siendo su madre la Reina Regente y consta de un artículo único y cuatro estipulaciones por las que se reservan a España ciertos privilegios que impidan la discriminación relacionados con las actividades de las órdenes religiosas, las actividades de empresas comerciales y agrícolas españolas y el establecimiento de de forma transitoria de depósitos de carbón para la armada y la marina mercante. En la cuarta estipulación se acuerda una compensación por la cesión de los territorios de 25 millones de pesetas, que serán entregados a España. Además ambas partes se otorgan la cláusula de la nación más favorecida. ${ }^{63}$

Alemania amplió su presencia en el Pacífico con las islas Carolinas, Palaos, islas Marianas, con la excepción de la isla de Guam, que fue cedida a Estados Unidos de América, además de las islas Salomón, incluida Bouganville y Buka, y, posteriormente, las mencionadas Marshall y Nauru. Tras la derrota de Alemania durante la I Guerra Mundial, Japón retuvo los archipiélagos por mandato de la Sociedad de Naciones, demostrando una vez más la falta de visión geopolítica en una zona de tan gran valor geoestratégico. España había permanecido neutral durante el conflicto mundial y fue incapaz de imponer su derecho a recuperar sus antiguas colonias en el Pacífico al final de la contienda.

63. La redacción oficial de las partes más importantes de la "Ley autorizando al Gobierno para ceder al Imperio de Alemania las islas Carolinas con las Palaos y las Marianas, excepto Guam”, es: “Articulo único. Se autoriza al Gobierno para ceder al Imperio de Alemania las islas Carolina con las Palaos y las Marianas, excepto Guam, dentro de las estipulaciones que siguen: Primera. El Imperio Alemán reconocerá en dichas islas á las órdenes religiosas españolas los mismos derechos y las mismas libertades que reconozca á las misiones de las órdenes religiosas alemanes. Segundo. El Imperio Alemán dará al comercio y á los establecimientos agrícolas españoles el mismo trato y las mismas facilidades que dé en los referidos Archipiélagos á los establecimientos agrícolas y al comercio de súbditos alemanes. Tercera. España podrá establecer y conservar, aun en tiempos de guerra, un depósito de carbón para la Marina de guerra y mercantes en el Archipiélago de las Palaos y otro en el Archipiélago de las Marianas. Cuarta. El Imperio Alemán indemnizará la cesión de los territorios supradichos mediante la suma de 25 millones de pesetas, que serán abonados á España... Dado en Palacio á veinticuatro de Junio de mil ochocientos noventa y nueve. Yo la Reina Regente. El ministro de Estado. Francisco Silvela" (Gaceta de Madrid, 1899, p., 1151). 


\section{Conclusiones}

La geopolítica tiene sus fundamentos modernos a partir del "reparto del mundo conocido" entre las dos potencias marinas europeas del siglo XV, Portugal y España, el desarrollo de la navegación y las nuevas técnicas para la construcción de navíos no fueron factores fundamentales en los dos siglos siguientes. El océano Pacífico fue, desde el principio de su descubrimiento para los europeos un "mar español" al que llegaron mucho más tarde, neerlandeses, británicos, franceses y estadounidenses. La importancia de la "colonización" del océano llamado Pacífico por Magallanes, fue no solo política sino fundamentalmente comercial. De ahí el interés de las potencias europeas en sus contactos con las civilizaciones ribereñas del océano para, sin rubor, utilizar la imposición mediante la "diplomacia de las cañoneras". En el artículo comprobamos que la historia la escribieron los europeos, que se consideraron a así mismos "descubridores y conquistadores", ignorando que ya existían pueblos más antiguos con su propia historia en el Pacífico.

España desarrolló la primera ruta comercial global mediante el "Galeón de Manila”, entre Asia y América y convirtió a este continente en centro de la corriente mercantilista durante dos siglos. Además, estableció el primer sistema monetario global con la utilización masiva del "real de a ocho" conocido como el "dólar español", "peso mexicano" o simplemente "peso". Era la moneda universal, que hasta 1857 fue la moneda de curso legal en Estados Unidos de América y modelo para la adopción de las propias monedas en los países que utilizan el dólar, incluida China y Japón que las utilizaron como referencia. No hay ninguna duda de que desde las exploraciones de las riberas americanas del océano Pacífico hasta la ocupación de los nuevos territorios isleños fue una tarea que preparó los fundamentos geopolíticos actuales del gran océano. Todo ello fue posible a la debilidad de dos imperios de pies de barro dormidos: China y Japón.

Por lo tanto, hemos seguido un método histórico geográfico donde los "colonizadores" se suceden de forma temporal en unos territorios comunes pero es innegable que España fue pionera con su aventura geográfica en el mar Océano. Este trabajo está enfocado en la evolución de la presencia de los dos imperios, desde el siglo XVIII, que finalmente se enfrentaron en el océano Pacífico: el Imperio colonial español y el Imperio estadounidense que, en ambos casos acudieron al Pacífico por la fuerza de atracción que ejercían otros dos imperios locales: el Imperio chino y el Imperio del Sol naciente. La 
falta de poder de contención de ambos imperios asiáticos delinearon el mapa geopolítico de los siglos xx y Xxi. La recuperación de Japón tras la II Guerra mundial se debió a la estructura político-económica desarrollada durante el siglo XIX, y el desarrollo espectacular de China tiene sus raíces en el espectro geopolítico establecido por la política imperialista occidental en los siglos anteriores, que promovió la unidad del gigante asiático.

El siglo Xx se iniciaba para España con el "desastre del 98" que ponía prácticamente fin al Imperio español, concebido como una organización teocrática y difusora de los principios religiosos más conservadores y el nacimiento de un nuevo imperialismo. Se producía una auténtica transición geopolítica. La falta de visión geopolítica de España y la falta de preparación de los gobernantes para comprender la importancia de la geoestrategia a largo plazo hizo del Imperio español un gigante de pies de barro. El español era un Imperio sin una flota permanente, hasta bien entrado el siglo XVIII, y su ausencia en una nación peninsular influyó en la dificultad de defender los territorios al carecer de la población necesaria. Sin embargo, no hay que olvidar que el Imperio español realizó una inmensa aportación a la economía del mundo mediante el intercambio cultural y de productos autóctonos. Estableció la primera ruta comercial globalizada y la primera moneda global, el "real de a ocho" denominado "Spanish dollar" o "Peso mexicano" cuya utilización se extendió por el continente americano y por los países asiáticos bañados por el océano Pacífico. España fue, después de los romanos, el mayor planificador de ciudades y obras civiles y hoy aun quedan infinitas huellas de su obra, a pesar de que en algunas colonias los enemigos de España pusieron mucho empeño en su desaparición. ${ }^{64}$

La sustitución de la larga soberanía española en extensos territorios isleños del Pacífico por el imperialismo estadounidense fue una gran estrategia geopolítica y neoeconómica. El centro de gravedad de la política se ha trasladado desde el océano Atlántico hacia el océano Pacífico y las nuevas potencias políticas y económicas de los próximos siglos surgirán de sus entrañas. Las teorías de Grocio triunfaron, es decir la libertad de comerciar, pero la realidad es que los ganadores no respetaron los derechos de los oriundos de los

64. Curiosamente aun permanece la influencia del idioma español en algunos idiomas nativos de los archipiélagos del océano Pacífico. El chabacano, con gran influencia del español se utiliza en Zamboanga (Filipinas) y el chamorro es la lengua autóctona de las islas Marianas y Guam con vocabulario español. 
territorios del Pacífico. Tanto los neerlandeses como los británicos defendieron la "libertad de los mares" hasta que se apoderaron de sus riquezas. No obstante, hemos comprobado a lo largo del trabajo que las teorías al servicio de las naciones pueden ser utilizadas durante períodos limitados, para ser sustituidas por otras al servicio de los nuevos imperios. Para España la libertad de los mares fue un límite a su monopolio explorador, para su sucesor en el Pacífico, Estados Unidos de América, solo fue un punto de partida para su expansionismo durante los siglos XIX y XX.

\section{Referencias}

Cólogan, C. (2015). Bernardo Cólogan y los 55 Días en Pekín. Santa Cruz deTenerife, España: Ministerio de Asuntos Exteriores.

Empire of Japan Treaty, Kanagawa, March 31, 1854. Treaty between the United States of America and the Empire of Japan. (1854). [Consultado en U.S. Sen., Exec. Docs., 33rd, 2nd (1854-5), Vol. 6, \#34, pp. 153-5].

Encyclopædia Britannica. (1898). Signing of the Treaty of Paris. [Imagen] Recuperado de https:/www.britannica.com/event/Treaty-of-Paris-1898/ images-videos

Frédéric, L. (2002). Japan Encyclopedia. Cambridge, Massachusetts, London, England: The Belknap Press of Harvard University Press.

Gaceta de Madrid. (20 de febrero de 1886). Núm. 51, pp. 522-524. [Recuperado de https://www.boe.es/datos/pdfs/BOE//1886/051/A00522-00524.pdf]. Gaceta de Madrid. (29 de junio de 1899). Año CCXXXVIII, Núm. 180, Tomo II, p. 1151. [Recuperado de https://www.boe.es/datos/pdfs/ BOE//1899/180/A01151-01151.pdf].

Gaceta de Madrid. (24 de agosto de 1901). Año CCXL, Núm. 236, Tomo III, p. 983. [Recuperado de https://www.boe.es/datos/pdfs/BOE//1901/236/ A00983-00983.pdf].

Guano Islands. An act to authorize protection to be given to citizens of the United States who may discover deposites of guano. (1856). Chap. CLXIV, Thirty-fourth Congress. Sess. I. Ch. 164, 1855, pp. 119-120.

Hawks, F. L. (1856). Narrative of the Expedition of An American Squadron. The China Seas and Japan. Performed in the years 1852, 1853 and 1854 under the command of Commodore M.C. Perry, United States Navy, by order of the government of the United States. Washington, United States: Beverly Tucker, Senate Printer. 
Lenin, V. I. (1917). L’impérialisme, stade suprême du capitalisme [El imperialismo, fase superior del capitalismo].

Mackinder, H. J. (1902). Britain and the British Seas. London: William Heinemann.

Mackinder, H. J. (1919). Democratic Ideals and Reality. A Study in the Politics of Reconstruction. London: Constable and Company LTD.

Modelski, G. (1987). Long Cycles in Global Politics. London: Palgrave Macmillan. doi: 10.1007/978-1-349-09151-5

Polo, M. (s.f.). Marco Polo: El libro de las maravillas. Salamanca, España: Ediciones generales Anaya.

Taylor, P. J. (1985). Political Geography: World Economy, Nation-State and Locality. London and New York: Editorial Longman.

Treaty between Her Majesty and the Emperor of China, signed, in the English and Chinese languages, at Nanking, August 29, 1842. (7 de noviembre de 1843). The London Gazette. (20276), pp. 3595-3638. Recuperado de https://www.thegazette.co.uk/London/issue/20276/data.pdf

Tratado de Madrid. (1750). [Tratado de las coronas de España y Portugal para definir los límites de sus colonias en América y Asia].

Tratado de Tordesillas. (1494). [Versión facsimilar del Ministerio de Educación y Ciencia].

Treaty de Of Tianjin (Tien-Tsin): 1858. (1858). [Consultado en USC US-China Institute].

Vila, C. (2007). Toma de Manila por los ingleses en 1762. Anuario de Estudios Atlánticos, 1(53), 167-220. Recuperado de http://anuariosatlanticos. casadecolon.com/index.php/aea/article/view/907 